\title{
Plasma Levels of Receptor-interacting Protein Kinase 3 Is Associated With Postoperative Acute Kidney Injury in Acute DeBakey Type I Aortic Dissection.
}

\section{Lei Wang}

Fujian Medical University Union Hospital

\section{Guodong Zhong}

the Second People's Hospital of Fujian University of Traditional Chinese Medicine Hao Zhou

Fujian Medical University Union Hospital

Xiaochai Lv

Fujian Medical University Union Hospital

\section{Yi Dong}

Fujian Medical University Union Hospital

\section{Xiaoli Wang}

Fujian Medical University Union Hospital

\section{Xiaofu Dai}

Fujian Medical University Union Hospital

\section{Yanfang Xu}

First Affiliated Hospital of Fujian Medical University

\section{LiangWan Chen ( $\sim$ clw1259@163.com )}

Union Hospital of Fujian Medical University https://orcid.org/0000-0002-4001-6387

\section{Research article}

Keywords: acute DeBakey type I aortic dissection, acute kidney injury, necroptosis, receptor-interacting protein kinase 3

Posted Date: June 28th, 2021

DOl: https://doi.org/10.21203/rs.3.rs-634726/v1

License: (c) (i) This work is licensed under a Creative Commons Attribution 4.0 International License. Read Full License 
Version of Record: A version of this preprint was published at Journal of Cardiothoracic Surgery on March 15th, 2022. See the published version at https://doi.org/10.1186/s13019-022-01783-0. 


\section{Abstract}

Background. Postoperative acute kidney injury (AKI) in acute Debakey type I aortic dissection (ADIAD) is common but has unclear pathogeneses and limited treatments. Receptor-interacting protein kinase 3 (RIP3), a mediator of necroptosis, is associated with human sepsis-induced and posttraumatic AKI, but its role in human postoperative AKI in ADIAD remains unclear. We assumed that RIP3 levels is associated with postoperative AKI in ADIAD.

Methods. Plasma samples and the clinical data of continuous patients with ADIAD were collected prospectively. The patients were divided into three groups according to AKI stage postoperatively. The plasma RIP3 levels were compared among the groups, and the relationship between RIP3 and serum creatinine (sCr), inflammatory cytokines as well as clinical results were analyzed.

Results. Eighty patients were enrolled. The postoperative and elevated RIP3 levels among the three groups were significantly different $(P<0.0001)$, both with a positive trend across the AKI stage ( $P$ for trend $<0.001)$, and they were also independent risk factors for postoperative AKI in ADIAD $(O R=1.018$ and $1.026, P<0.05)$. The postoperative RIP3 levels were positively correlated with the aortic crossclamp time $(R=0.253, P<0.05)$; the peak values of $\mathrm{sCr}$, procalcitonin, interleukin- 6 and lactate postoperatively; the mechanical ventilation time; and the ICU stay time $(R=0.66,0.369,0.409,0.397,0.474$ and 0.435 , respectively; all $P<0.001)$. Plasma RIP3 level and sCr were comparable in diagnosing postoperative AKI in ADIAD $(P=0.898)$, and higher postoperative RIP3 level was associated with lower survival rate.

Conclusion. The plasma RIP3 levels are associated with postoperative AKI, inflammatory response and clinical outcomes in ADIAD.

\section{Background}

Acute DeBakey type I aortic dissection (ADIAD) is the most critical condition in cardiovascular diseases, with most patients requiring emergency surgery. Cardiac surgery-associated acute kidney injury (AKI) is the second most common cause of AKI, except sepsis ${ }^{[1]}$, and the incidence of postoperative AKI in aortic dissection $(A D)$ is higher than that of other cardiac surgeries ${ }^{[2]}$, as high as $18 \%-67 \%{ }^{[3,4]}$. Postoperative $A K I$ in $A D$ is also an independent risk factor for postoperative death and major complications ${ }^{[5,6]}$. However, its pathogenesis remains unclear, and no reliable drugs or specific treatments are available to prevent or cure AKI, except renal replacement therapy (RRT) ${ }^{[1,7]}$. But in fact, the prognosis of RRT after $A D$ repair is not ideal ${ }^{[8]}$; thus, challenges persist in this field.

Necroptosis is a new form of programmed cell death that is different from necrosis and apoptosis. Receptor-interacting protein 1 (RIP1)-RIP3-mixed lineage kinase domain-like protein (MLKL) is the bestcharacterized pathway of necroptosis. Stimulus signals promote the formation of necrosome, leading to cell rupture with inflammatory cytokines release. The latter and RIP3 can promote the formation of inflammasomes, leading to a self-amplifying cycle of inflammation and necroptosis ${ }^{[9]}$ called 
necroinflammation. Recent studies have also found other necroptosis pathways that are independent of RIP1 and MLKL ${ }^{[10]}$, but RIP3 is necessary. Necroptosis is associated with renal ischemia-reperfusion injury and cisplatin-induced AKI ${ }^{[11,12]}$, and knocking out the RIP3 gene or RIP3 inhibitor can protect mice with renal ischemia-reperfusion injury from severe $\mathrm{AKI}{ }^{[11]}$; thus, necroptosis may be a new therapeutic target for AKI.

The pathogenesis of postoperative AKI in AD is unique. Injury to renal tubular epithelial cells may be caused by comprehensive factors, such as renal malperfusion when the aorta is torn ${ }^{[13]}$, severe secondary inflammation during extracorporeal circulation and surgery ${ }^{[14]}$ and ischemia-reperfusion injury during deep hypothermic circulatory arrest. Fewer necroptosis studies have been reported concerning human AKI. Since necroptotic cells can release RIP3 into the circulation, the plasma RIP3 levels can be detected to reflect necroptosis. Currently, only three human studies have shown that the plasma RIP3

levels are associated with sepsis-induced or posttraumatic AKI ${ }^{[15-17]}$, and several studies have shown that the plasma RIP3 levels are correlated with the severity of sepsis, coronary heart disease or heart failure in humans ${ }^{[18-21]}$. However, no study has been published on the correlation between postoperative $A K I$ in $A D$ and necroptosis or RIP3. This study primarily aimed to analyze the correlation between the plasma RIP3 levels and postoperative AKI in ADIAD for the first time. The secondary aim was to analyze the correlation between the postoperative RIP3 levels and serum creatinine (sCr), inflammatory cytokines and clinical outcomes. We assumed that RIP3 and necroptosis, as well as necroinflammation, play important roles in the occurrence and development of postoperative AKI in ADIAD; thus, plasma RIP3 level may be a new predictor and potential therapeutic targets of postoperative AKI in ADIAD.

\section{Materials And Methods}

Patients: This was a prospective observational cohort study. Perioperative plasma samples and clinical data were collected from continuous patients diagnosed with ADIAD in cardiovascular surgery at Union Hospital of Fujian Medical University from August 2020 to January 2021. One hundred and thirty-three patients were enrolled into the cohort, and 80 patients met the inclusion and exclusion criteria. Inclusion criteria: (1) patients were diagnosed with ADIAD by computed tomography angiography (CTA) of the thoracic and abdominal aorta and echocardiography and received AD surgery under moderate hypothermia circulation arrest within 5 days of AD onset; and (2) the surgical methods were artificial vascular replacement of the ascending aorta and hemiarch combined with open implantation of a triplebranched stent in the descending aorta pioneered by Professor Liangwan Chen [22]. Exclusion criteria: (1) aortic intramural hematoma; (2) posttraumatic AD; (3) patients with preoperative chronic renal failure who had received RRT; (4) patients who died or discontinued treatment within 48 hours after surgery; and (5) incomplete collection of plasma samples or samples with hemolysis. At the same time, the venous plasma RIP3 levels was detected from 20 age-and-sex matched volunteers as control group from physical examination center at the hospital. The flow chart of the included cases is shown in Fig. 1. 
Diagnosis and Definitions: (1) Diagnosis for postoperative AKI: The patients were diagnosed with no-AKI, AKI stage 1, AKI stage 2 and AKI stage 3 according to the Kidney Disease Improving Global Outcomes (KDIGO) criteria ${ }^{[23]}$ within 7 days postoperatively. Because of the relatively small number of patients with AKI stage 3 , we combined patients with AKI stage 2 and stage 3 into one group. AKI was defined as a sCr value increased by $\geq 26.5 \mu \mathrm{mol} / \mathrm{L}$ within 48 hours or an $\mathrm{sCr}$ value increased by $50 \%$ within 7 days after surgery compared with the baseline value at admission. (2) Diagnosis for malperfusion of AD: Comprehensive diagnosis was made according to preoperative CTA indicating decreased blood flow or complete artery occlusion, clinical manifestations such as coma or abdominal pain, and laboratory test results such as elevated $\mathrm{sCr}$ or myocardial enzyme. (3) Hypotension is defined as blood pressure < $90 / 60 \mathrm{mmHg}$ on admission.

Collection and detection of plasma samples: Five milliliters of radial arterial blood was collected in an EDTA anticoagulant tube preoperatively after anesthesia and approximately 40 hours after surgery. The plasma samples were centrifuged immediately (1000 g for $15 \mathrm{~min}$ ) after collection or refrigerated in a $4^{\circ} \mathrm{C}$ refrigerator and centrifuged within 4 hours. They were then separated into EP tubes and immediately placed in a $-80^{\circ} \mathrm{C}$ refrigerator. The RIP3 levels were measured using commercial enzyme-linked immunosorbent assay kits (CUSABIO, Wuhan, China) within 3 months of sample collection. The tester strictly followed the kit instructions and was blind to the AKI stage of the patients.

Statistical Methods: IBM SPSS 25.0 statistical software and Medcalc software were used for statistical analysis. The measurement data are presented as the mean \pm standard deviation (for normally distributed data) or the median with interquartile range (IQR) (for nonnormally distributed data). The categorical data are presented as counts and percentages. One-way analysis of variance (for measurement and normally distributed data), the Kruskal-Wallis test (for measurement and nonnormally distributed data), chisquared test or Fisher's exact test (for categorical data) were used to compare the clinical data among the three groups. Bonferroni analysis was used for pairwise comparisons among the three groups, and a linear trend test was performed for the postoperative and elevated RIP3 levels across the three groups. The independent risk factors for postoperative AKI in ADIAD were analyzed by univariate and multivariate logistic regression. Pearson's or Spearman's correlation tests were used to analyze the correlation between the plasma RIP3 levels and clinical parameters. Receiver operating characteristic (ROC) curves of sCr and plasma RIP3 levels were compared to predict postoperative AKI. The Youden's index in the ROC curve was used to determine the optimal cut-off value of plasma RIP3 levels for predicting AKI in ADIAD. The Kaplan-Meier method was used to compare the survival rate among different postoperative RIP3 levels. $P<0.05$ was considered statistically significant.

\section{Results}

Perioperative clinical data of the patients. The mean age of the normal controls and patients was (53.24 $\pm 10.23)$ years $V S(54.33 \pm 11.80)$ years $(P \otimes 0.05) ; 15(75.0 \%)$ and $58(72.5 \%)$ patients were male, respectively $(P \otimes 0.05)$. The median collection time of the postoperative plasma samples was $40(33-43)$ hours. The plasma RIP3 levels of all samples were higher than the lowest detectable level $(>15.6 \mathrm{pg} / \mathrm{ml})$, 
and the RIP3 levels in 2 patients were decreased after surgery, while the others were all elevated. The preoperative plasma RIP3 levels in patients with ADIAD were significantly higher than those in normal controls [(921.5 \pm 185.8$) \mathrm{pg} / \mathrm{ml} \mathrm{VS}(761.4 \pm 120.6) \mathrm{pg} / \mathrm{ml}, P<0.01]$. The incidence rates of postoperative AKI and continuous RRT (CRRT) were $66.25 \%$ and $8.75 \%$, respectively, in 80 patients. The relationship between preoperative plasma RIP3 levels and clinical manifestations showed that patients with hypotension, higher $\mathrm{s} C r$ and renal malperfusion had higher RIP3 levels, but the last of the three had not yet reached a statistical difference (See Additional file 1). The patients were followed up for 60 days after surgery, and three patients died in hospital, and one died out of hospital. (Table 1) 
Table 1

Perioperative characteristics and plasma RIP3 levels of patients $(n=80)$.

\begin{tabular}{|c|c|c|c|c|c|}
\hline & $\begin{array}{l}\text { No AKI } \\
(n=27)\end{array}$ & $\begin{array}{l}\text { AKI stage } 1 \\
(n=29)\end{array}$ & $\begin{array}{l}\text { AKI stage } \\
2-3 \\
(n=24)\end{array}$ & $\begin{array}{l}F \text { or } H \\
\text { or } \\
\times 2 \\
\text { Value }\end{array}$ & $\begin{array}{l}P \\
\text { Value }\end{array}$ \\
\hline Male sex & $20(74.1)$ & $22(75.9)$ & $16(66.7)$ & 0.944 & 0.624 \\
\hline Age (years) & $52.2 \pm 13.0$ & $54.3 \pm 9.6$ & $56.4 \pm 12.7$ & 0.733 & 0.484 \\
\hline Body mass index (kg/囚) & $24.8 \pm 3.9$ & $25.9 \pm 4.0$ & $24.4 \pm 4.0$ & 2.000 & 0.377 \\
\hline \multicolumn{6}{|l|}{ Past medical history } \\
\hline Hypertension & $16(59.3)$ & $21(72.4)$ & $13(54.1)$ & 3.315 & 0.191 \\
\hline Cardiovascular surgery & $3(11.1)$ & $0(0)$ & $2(8.3)$ & 3.304 & 0.187 \\
\hline Marfan syndrome & $2(7.4)$ & $0(0)$ & $1(4.2)$ & 2.075 & 0.408 \\
\hline \multicolumn{6}{|l|}{ Preoperative items } \\
\hline $\begin{array}{l}\text { Left ventricular ejection fraction } \\
(\%)\end{array}$ & $64.7 \pm 5.2$ & $67.2 \pm 4.2$ & $60.8 \pm 9.4$ & 7.034 & 0.039 \\
\hline Pericardial tamponade & $2(7.4)$ & $1(3.4)$ & $2(8.3)$ & 0.773 & 0.731 \\
\hline Hypotension & $0(0)$ & $1(3.4)$ & $3(12.5)$ & 1.83 & 0.524 \\
\hline Serum creatinine (umol/L) & $\begin{array}{l}85.5(60.4- \\
137.2)\end{array}$ & $\begin{array}{l}79.5(68.2- \\
114.2)\end{array}$ & $\begin{array}{l}68.7(57.2- \\
114.0)\end{array}$ & 1.825 & 0.401 \\
\hline Serum creatinine $>135 \mathrm{umol} / \mathrm{L}$ & $7(25.9)$ & $3(10.3)$ & $4(16.7)$ & 2.446 & 0.341 \\
\hline Procalcitonin (ng/ml) & $\begin{array}{l}0.10(0.06- \\
0.35)\end{array}$ & $\begin{array}{l}0.05(0.03- \\
0.15)\end{array}$ & $\begin{array}{l}0.12(0.04- \\
0.27)\end{array}$ & 4.081 & 0.130 \\
\hline Interleukin-6 (pg/ml) & $\begin{array}{l}54.9(39.3- \\
110.3)\end{array}$ & $\begin{array}{l}38.3(31.2- \\
49.3)\end{array}$ & $\begin{array}{l}55.4(39.1- \\
89.9)\end{array}$ & 6.883 & 0.032 \\
\hline C-reactiveprotein (mg/L) & $\begin{array}{l}6.8(2.9- \\
59.3)\end{array}$ & $3.4(2.2-9.0)$ & $\begin{array}{l}10.3(4.6- \\
23.2)\end{array}$ & 5.046 & 0.080 \\
\hline Malperfusion syndrome & $7(25.9)$ & $9(31.0)$ & $6(25.0)$ & 0.472 & 0.813 \\
\hline Cerebral malperfusion & $2(7.4)$ & $4(13.8)$ & $2(8.3)$ & 0.808 & 0.720 \\
\hline Extremity malperfusion & $2(7.4)$ & $3(10.3)$ & $2(8.3)$ & 0.323 & 1.000 \\
\hline Renal malperfusion & $1(3.7)$ & $2(6.9)$ & $1(4.2)$ & 0.570 & 1.000 \\
\hline
\end{tabular}

Data are presented as mean \pm standard deviation or median (interquartile range) or $n(\%)$.

RIP3 = receptor-interacting protein-3 


\begin{tabular}{|c|c|c|c|c|c|}
\hline & $\begin{array}{l}\text { No AKI } \\
(n=27)\end{array}$ & $\begin{array}{l}\text { AKI stage } 1 \\
(n=29)\end{array}$ & $\begin{array}{l}\text { AKI stage } \\
2-3 \\
(n=24)\end{array}$ & $\begin{array}{l}F \text { or } H \\
\text { or } \\
\times 2 \\
\text { Value }\end{array}$ & $\begin{array}{l}P \\
\text { Value }\end{array}$ \\
\hline Mesenteric malperfusion & $2(7.4)$ & $1(3.4)$ & $2(8.3)$ & 0.773 & 0.731 \\
\hline Coronary malperfusion & $0(0)$ & $0(0)$ & $2(8.3)$ & 0.472 & 0.813 \\
\hline \multicolumn{6}{|l|}{ Type of combined surgery } \\
\hline Aortic valvuloplasty & $17(63.0)$ & $16(55.2)$ & $14(58.3)$ & 0.397 & 0.820 \\
\hline Bentall & $2(7.4)$ & $3(10.3)$ & $5(20.8)$ & 1.809 & 0.397 \\
\hline Coronary artery bypass grafting & $0(0)$ & $0(0)$ & $2(8.3)$ & 2.974 & 0.096 \\
\hline Mitral valve replacement & $0(0)$ & $0(0)$ & $1(4.2)$ & 1.961 & 0.315 \\
\hline \multicolumn{6}{|l|}{ Intraoperative items } \\
\hline $\begin{array}{l}\text { Lowest Nasopharyngeal } \\
\text { temperature }\left({ }^{\circ} \mathrm{C}\right)\end{array}$ & $\begin{array}{l}23.0(22.1- \\
23.7)\end{array}$ & $\begin{array}{l}22.5(22.0- \\
22.8)\end{array}$ & $\begin{array}{l}22.9(22.0- \\
23.1)\end{array}$ & 5.444 & 0.066 \\
\hline $\begin{array}{l}\text { Extracorporeal circulation time } \\
(\mathrm{min})\end{array}$ & $\begin{array}{l}131.5 \\
(120.5- \\
139.5)\end{array}$ & $\begin{array}{l}137.0 \\
(117.7- \\
155.0)\end{array}$ & $\begin{array}{l}153.0 \\
(126.0- \\
165.0)\end{array}$ & 4.790 & 0.091 \\
\hline Aortic crossclamp time (min) & $51.9 \pm 14.4$ & $55.9 \pm 16.1$ & $66.0 \pm 19.7$ & 4.426 & 0.015 \\
\hline $\begin{array}{l}\text { Moderate hypothermia circulation } \\
\text { arrest time (min) }\end{array}$ & $16.0 \pm 3.7$ & $15.5 \pm 4.7$ & $16.0 \pm 3.6$ & 1.026 & 0.867 \\
\hline $\begin{array}{l}\text { Red blood cells transfused volume } \\
\text { (U) }\end{array}$ & $4(4-6)$ & $6(4-6)$ & $6(4-8)$ & 11.034 & 0.004 \\
\hline Plasma transfused volume (ml) & $\begin{array}{l}523.08 \pm \\
230.85\end{array}$ & $\begin{array}{l}603.84 \pm \\
206.36\end{array}$ & $\begin{array}{l}613.04 \pm \\
294.34\end{array}$ & 0.981 & 0.430 \\
\hline \multicolumn{6}{|l|}{ Postoperative items } \\
\hline Peak creatinine (umol/L) & $\begin{array}{l}103.5(75.1- \\
141.2)\end{array}$ & $\begin{array}{l}130.5 \\
(114.6- \\
175.5)\end{array}$ & $\begin{array}{l}219(143- \\
474)\end{array}$ & 23.458 & 0.000 \\
\hline Peak procalcitonin (ng/ml) & $\begin{array}{l}1.72(0.85- \\
3.78)\end{array}$ & $\begin{array}{l}1.01(0.70- \\
3.40)\end{array}$ & $\begin{array}{l}5.18(1.91- \\
12.60)\end{array}$ & 14.870 & 0.001 \\
\hline Peak interleukin-6 (pg/ml) & $\begin{array}{l}163.4 \\
(141.0- \\
273.1)\end{array}$ & $\begin{array}{l}197.9 \\
(166.4- \\
249.9)\end{array}$ & $\begin{array}{l}284.2 \\
(270.1- \\
321.7)\end{array}$ & 18.822 & 0.000 \\
\hline
\end{tabular}

Data are presented as mean \pm standard deviation or median (interquartile range) or $\mathrm{n}(\%)$. RIP3 = receptor-interacting protein-3 


\begin{tabular}{|c|c|c|c|c|c|}
\hline & $\begin{array}{l}\text { No AKI } \\
(n=27)\end{array}$ & $\begin{array}{l}\text { AKI stage } 1 \\
(n=29)\end{array}$ & $\begin{array}{l}\text { AKI stage } \\
2-3 \\
(n=24)\end{array}$ & $\begin{array}{l}F \text { or } H \\
\text { or } \\
\times 2 \\
\text { Value }\end{array}$ & $\begin{array}{l}P \\
\text { Value }\end{array}$ \\
\hline Peak lactate (mmol/L) & $\begin{array}{l}3.10(2.50- \\
4.30)\end{array}$ & $\begin{array}{l}3.70(2.55- \\
4.95)\end{array}$ & $\begin{array}{l}7.10(3.68- \\
9.73)\end{array}$ & 12.095 & 0.002 \\
\hline Peak C-reactiveprotein (mg/L) & $\begin{array}{l}211.09 \pm \\
59.42\end{array}$ & $\begin{array}{l}229.28 \pm \\
49.75\end{array}$ & $\begin{array}{l}243.30 \pm \\
59.5\end{array}$ & 1.943 & 0.151 \\
\hline $\begin{array}{l}\text { Extracorporeal membrane } \\
\text { oxygenation }\end{array}$ & $0(0)$ & $0(0)$ & $2(8.3)$ & 2.974 & 0.096 \\
\hline Mechanical ventilation time $(\mathrm{h})$ & $\begin{array}{l}19.0(14.5- \\
39.7)\end{array}$ & $\begin{array}{l}21.0(16.7- \\
34.0)\end{array}$ & $\begin{array}{l}72.0(33.2- \\
112.0)\end{array}$ & 18.172 & 0.000 \\
\hline ICU stay time (h) & $\begin{array}{l}55.0(39.7- \\
72.0)\end{array}$ & $\begin{array}{l}57.2(41.5- \\
89.5)\end{array}$ & $\begin{array}{l}122.5(68.5- \\
171.2)\end{array}$ & 16.297 & 0.000 \\
\hline In-hospital mortality & $0(0)$ & $0(0)$ & $3(12.5)$ & 4.628 & 0.028 \\
\hline \multicolumn{6}{|l|}{ Plasma RIP3 levels (pg/ml) } \\
\hline Preoperative RIP3 levels & $\begin{array}{l}905.4 \pm \\
183.9\end{array}$ & $\begin{array}{l}877.7 \pm \\
134.0\end{array}$ & $\begin{array}{l}987.7 \pm \\
223.7\end{array}$ & 2.820 & 0.138 \\
\hline Postoperative RIP3 levels & $\begin{array}{l}1007.4 \pm \\
195.8\end{array}$ & $\begin{array}{l}1101.3 \pm \\
141.4\end{array}$ & $\begin{array}{l}1394.5 \pm \\
160.6\end{array}$ & 34.331 & 0.000 \\
\hline Elevated RIP3 levels & $\begin{array}{l}101.9 \pm \\
66.7\end{array}$ & $223.6 \pm 89.5$ & $\begin{array}{l}406.8 \pm \\
159.1\end{array}$ & 44.947 & 0.000 \\
\hline \multicolumn{6}{|c|}{ Data are presented as mean \pm standard deviation or median (interquartile range) or $n(\%)$. } \\
\hline RIP3 = receptor-interacting pro & & & & & \\
\hline
\end{tabular}

Comparison of the plasma RIP3 levels among the three groups. The plasma RIP3 levels were significantly higher in the three groups after surgery than before surgery $(P<0.001)$. No differences were found in the preoperative plasma RIP3 levels among the three groups, but there were significant differences in postoperative and elevated RIP3 levels $(P<0.0001)$ with positive linear trends across the AKI stage $(P$ for trend $<0.001$ ) among the three groups. Pair comparisons of postoperative RIP3 levels among the three groups showed significant differences between the no-AKI and AKI stage 1 groups and between the noAKI and AKI stage $2-3$ groups $(P<0.0001)$. Pair comparisons of the elevated RIP3 levels among the three groups all showed significant differences $(P<0.0001)$. (Table 1 and Fig. 2$)$.

Risk factors for the postoperative AKI in ADIAD: The perioperative factors that might affect the occurrence of postoperative AKI in ADIAD were included in univariate and multivariate logistic regression, and the independent risk factors were the postoperative RIP3 level $(O R=1.018 ; 95 \% \mathrm{Cl}$. 1.009-1.023; $P<$ 
$0.05)$, the elevated RIP3 level $(O R=1.026 ; 95 \% \mathrm{Cl}$. 1.012-1.040; $P<0.05)$, and the aortic crossclamp time (ACCT) $(O R=1.067 ; 95 \%$ Cl: 1.003-1.134; $P<0.05)$. (Table 2)

Table 2

Univariate and multivariate logistic regression analysis of postoperative AKI in ADIAD

\begin{tabular}{|c|c|c|c|c|}
\hline & Univariate & & Multivariate & \\
\hline & OR $(95 \% \mathrm{Cl})$ & $\begin{array}{l}P \\
\text { Value }\end{array}$ & OR $(95 \% \mathrm{Cl})$ & $\begin{array}{l}P \\
\text { Value }\end{array}$ \\
\hline Age & - & 0.292 & - & - \\
\hline Body mass index & - & 0.671 & - & - \\
\hline Extracorporeal circulation time & - & 0.146 & - & - \\
\hline Aortic crossclamp time & $\begin{array}{l}1.006(1.003- \\
1.009)\end{array}$ & 0.044 & $\begin{array}{l}1.067(1.003- \\
1.134)\end{array}$ & 0.039 \\
\hline $\begin{array}{l}\text { Red blood cell transfusion volume } \\
\text { intraoperatively }\end{array}$ & $\begin{array}{l}1.598(1.122- \\
2.276)\end{array}$ & 0.009 & - & 0.256 \\
\hline Plasma transfusion volume intraoperatively & - & 0.169 & - & - \\
\hline $\begin{array}{l}\text { Peak lactate values within } 7 \text { days } \\
\text { postoperatively }\end{array}$ & $\begin{array}{l}1.040(1.325- \\
1.687)\end{array}$ & 0.023 & - & 0.651 \\
\hline $\begin{array}{l}\text { Peak interleukin- } 6 \text { values within } 7 \text { days } \\
\text { postoperatively }\end{array}$ & - & 0.075 & - & 0.119 \\
\hline $\begin{array}{l}\text { Peak C-reactiveprotein values within } 7 \text { days } \\
\text { postoperatively }\end{array}$ & - & 0.084 & - & 0.087 \\
\hline $\begin{array}{l}\text { Postoperative RIP3 levels about } 40 \mathrm{~h} \\
\text { postoperatively }\end{array}$ & $\begin{array}{l}1.006(1.003- \\
1.009)\end{array}$ & 0.000 & $\begin{array}{l}1.018(1.009- \\
1.023)\end{array}$ & 0.012 \\
\hline Elevated RIP3 levels & $\begin{array}{l}1.023(1.012- \\
1.034)\end{array}$ & 0.000 & $\begin{array}{l}1.026(1.012- \\
1.040)\end{array}$ & 0.002 \\
\hline
\end{tabular}

Correlation of the RIP3 levels with clinical parameters. The preoperative RIP3 levels were positively correlated with preoperative $\mathrm{sCr}$ levels $(R=0.535 ; P<0.001)$; The postoperative RIP3 levels were positively correlated with ACCT $(R=0.253 ; P<0.05)$; the peak values of $\mathrm{sCr}$, procalcitonin (PCT), interleukin-6 (IL-6) and lactate within 7 days postoperatively; the mechanical ventilation time; and the ICU stay time $(R=0.66$, $0.369,0.409,0.397,0.474$ and 0.435 , respectively; all $P<0.001$ ). (Fig. 3 )

Since there was a significant positive correlation between plasma RIP3 and sCr levels, the ROC curves were further made and indicating that the plasma RIP3 was comparable to $\mathrm{sCr}$ in diagnosing postoperative AKI in ADIAD ( $P=0.898$ ) (Fig. 4). According to the ROC curve, the optimal cut-off value of 
postoperative plasma RIP3 level in predicting postoperative AKI in ADIAD was $1263 \mathrm{pg} / \mathrm{ml}$. Accordingly, the patients were divided into a group with RIP3 levels $>1263 \mathrm{pg} / \mathrm{ml}$ and a group with RIP3 levels $<1263$ $\mathrm{pg} / \mathrm{ml}$. The survival rate at 60 days after surgery was lower in the group with higher postoperative RIP3 levels (LogRank $P<0.05)$ (Fig. 5)

\section{Discussion}

In this cohort study, only ADIAD patients undergoing triple-branched stent implantation surgery were included, and patients with aortic intramural hematoma with relatively lower inflammatory response were excluded. Although the plasma RIP3 levels were associated with hypotension and higher sCr levels, there was no difference in the incidence of the fore-mentioned preoperative complications as well as malperfusion syndrome among the three groups. Thus the patients were relatively homogeneous in the three groups.

The preoperative plasma RIP3 levels in renal malperfusion group was higher, but with no statistical significance, which might be associated with only unilateral renal malperfusion and the renal function was compensated by the other renal. The plasma RIP3 level was higher than control groups, and postoperative RIP3 level was higher than preoperative levels. This could be explained by a secondary inflammatory blow. On the other hand, no difference was found in preoperative plasma RIP3 levels among the different AKI stage groups, but the postoperative and elevated RIP3 levels were significantly different among the three groups and showed positive linear trends across the AKI stage. Additionally, the postoperative plasma RIP3 levels were significantly elevated in all three groups. Besides, the preoperative and postoperative RIP3 levels were positively correlated with $\mathrm{sCr}$, and the comparison of ROC curves of this two biomakers further showed that the plasma RIP3 levels was similar to $\mathrm{sCr}$ in diagnosing postoperative AKI in ADIAD. All these might indicate that the surgery and extracorporeal circulation promoted the necroptosis in kidney, and the postoperative plasma RIP3 levels might originate from the injured kidney. Hence the postoperative plasma RIP3 levels might show as a new biomaker in postoperative AKI in ADIAD.

Our study also indicated that the postoperative and elevated plasma RIP3 levels and ACCT were independent risk factors for postoperative AKI in ADIAD, and the postoperative RIP3 levels were significantly positively correlated with the ACCT. This is consistent with the research review ${ }^{[1]}$ indicating that ACCT is an independent risk factor for postoperative AKI in ADIAD. The longer the ACCT was, the longer the times of surgery, extracorporeal circulation and myocardial ischemia were. These effects could lead to more severe systemic inflammation, a necroptosis process that affects the recovery of postoperative cardiac function, malperfusion of visceral organs and more severe postoperative AKI. So necroptosis may participate in the occurrence and development of postoperative AKI in ADIAD during surgery and extracorporeal circulation. Additionally, our study also showed that the preoperative hypotension were associated with higher plasma RIP3 levels. This could also be explained by the fact that the cardiac function could affect renal perfusion. 
In addition, our study showed that the plasma RIP3 levels were significantly positively correlated with postoperative inflammatory cytokines such as PCT and IL-6, a finding that was consistent with a study showing a positive correlation between the plasma RIP3 and PCT levels in sepsis patients ${ }^{[19]}$. Both PCT and IL- 6 are acute reactive proteins with increased expression in the body under stress, and they are also increased in patients with $A D{ }^{[24,25]}$. The correlation between the plasma RIP3 levels and inflammatory cytokines also reflected the correlation between necroptosis and necroinflammation. A self-amplifying positive feedback cycle exists between necroptosis and necroinflammation, and RIP3 has a proinflammatory effect independent of the function of necroptosis ${ }^{[26,27]}$. Inhibition of RIP3 can inhibit necroptosis and necroinflammation ${ }^{[28]}$. The significant positive correlation between the plasma RIP3 levels and PCT and IL-6 showed that all three could serve as human hematology markers of necroptosis and necroinflammation ${ }^{[29]}$. Additionally, necroinflammation caused by necroptosis may further aggravate the occurrence and development of postoperative AKI in ADIAD, as well as prolong the postoperative mechanical ventilation time and ICU stay time, affecting the survival rate of patients. This finding was consistent with the results that the plasma RIP3 levels were correlated with the critical condition and prognosis in patients with coronary heart disease and heart failure ${ }^{[20,21]}$. Therefore, inhibiting necroptosis and controlling inflammation could be therapeutic targets for postoperative AKI in $A D I A D$, and the effect of controlling inflammation might be better and faster than that of inhibiting necroptosis pathways ${ }^{[29]}$.

Notably, some plasma samples were collected when the patients had undergone CRRT or extracorporeal membrane oxygenation (ECMO), during which the patient's blood was in direct contact with the surface of abiotic materials, significantly activating the inflammatory reaction of the body ${ }^{[30,31]}$. However, CRRT and ECMO can lead to blood dilution and pipeline adsorption of cytokines, and CRRT can filter some of the inflammatory cytokines ${ }^{[32]}$; thus, these factors may exert certain effects on the levels of RIP3 and inflammatory cytokines. However, in our study, the levels of inflammatory cytokines in patients who had undergone CRRT or ECMO were still very high, possibly because the plasma collection time was relatively early after surgery, and the severity of the inflammatory reaction in patients was significantly stronger than that of filtrating inflammatory cytokines, blood dilution and pipeline adsorption by CRRT.

The strengths of this study: The prospective cohort study and the included relatively homogeneous patients reduce the confounding bias. The limitations of this study: (1) The sample size was small. (2) Postoperative RIP3 was detected at only one time point without dynamic detection. (3) The urine RIP3 levels did not be detected. (4) Although there was a correlation between RIP3 levels and postoperative AKI stage in our study, no gold standard exists currently to detect necroptosis in humans. The elevated RIP3 levels cannot prove causally that necroptosis directly leads to the occurrence and development of postoperative AKI in ADIAD; further animal studies are warranted.

\section{Conclusions}


This study first analyzed the relationship between the plasma RIP3 levels and human postoperative AKI in ADIAD. The postoperative and elevated RIP3 levels were correlated with the severity of postoperative AKI, and postoperative RIP3 levels were correlated with inflammatory cytokines and patient clinical outcomes. These results suggest that necroptosis and necroinflammation may be involved in the occurrence and development of postoperative AKI in ADIAD, and they might be a new biomaker and potential therapeutic targets for postoperative AKI in ADIAD.

\section{Abbreviations}

RIP3: receptor-interacting protein kinase 3 ; AKI: acute kidney injury; ADIAD: acute DeBakey type I aortic dissection; sCr: serum creatinine; AD: aortic dissection; RRT: renal replacement therapy; RIP1: receptorinteracting protein 1; MLKL: mixed lineage kinase domain-like protein; CTA: computed tomography angiography; KDIGO: Kidney Disease Improving Global Outcomes; IQR: interquartile range; ROC: receiver operating characteristic; CRRT: continuous RRT; ACCT: aortic crossclamp time; PCT: procalcitonin, IL-6: interleukin-6; ECMO: extracorporeal membrane oxygenation.

\section{Declarations}

\section{Ethics approval and consent to participate:}

All procedures performed in studies involving human participants were in accordance with the 1964 Helsinki Declaration. The study was approved by the Bioethics Committee of the Union Hospital of Fujian Medical University (No. 2020WSJK042). Informed consent was obtained from all individual participants included in the study.

\section{Consent for publication:}

Not applicable.

\section{Availability of data and materials:}

The datasets during and/or analysed during the current study available from the corresponding author on reasonable request.

\section{Competing interests:}

The authors declare that they have no competing interests.

\section{Funding:}

This study was funded by Sponsored by Fujian provincial health technology project (2020QNB020) and the National Natural Science Foundation of China (U2005202).

\section{Authors' contributions:}


LW conceived and wrote the manuscript. XCL, YD, XLW collected the plasma. GDZ and HZ did the experiment, YFX, XFD and LWC reviewed the manuscript. All authors read and approved the final manuscript.

\section{Acknowledgements:}

Not applicable.

\section{References}

1. Wang Y, Bellomo R. Cardiac surgery-associated acute kidney injury: risk factors, pathophysiology and treatment. Nat Rev Nephrol. 2017;13:697-711.

2. Ko T, Higashitani M, Sato A, Uemura Y, Norimatsu T, Mahara K, et al. Impact of Acute Kidney Injury on Early to Long-Term Outcomes in Patients Who Underwent Surgery for Type A Acute Aortic Dissection. Am J Cardiol. 2015;116:463-8.

3. Mori Y, Sato N, Kobayashi Y, Ochiai R. Acute kidney injury during aortic arch surgery under deep hypothermic circulatory arrest. J Anesth. 2011;25:799-804.

4. Kim WH, Lee JH, Kim E, Kim G, Kim HJ, Lim HW. Can We Really Predict Postoperative Acute Kidney Injury after Aortic Surgery? Diagnostic Accuracy of Risk Scores Using Gray Zone Approach. Thorac Cardiovasc Surg. 2016;64:281-9.

5. Wang J, Yu W, Zhai G, Liu N, Sun LZ, Zhu JM. Independent risk factors for postoperative AKI and the impact of the AKI on 30-day postoperative outcomes in patients with type A acute aortic dissection: an updated meta-analysis and meta-regression. J Thorac Dis. 2018;10:2590-8.

6. Sasabuchi Y, Kimura N, Shiotsuka J, Komuro T, Mouri H, Ohnuma T, et al. Long-Term Survival in Patients With Acute Kidney Injury After Acute Type A Aortic Dissection Repair. Ann Thorac Surg. 2016;102:2003-9.

7. Joannidis M, Druml W, Forni LG, Groeneveld ABJ, Honore PM, Hoste E, et al. Prevention of acute kidney injury and protection of renal function in the intensive care unit: update 2017: Expert opinion of the Working Group on Prevention, AKI section, European Society of Intensive Care Medicine. Intensive Care Med. 2017;43:730-49.

8. Wang ZG, Ge M, Chen T, Chen C, Zong QY, Lu LC, et al. Independent risk factors and the long-term outcomes for postoperative continuous renal replacement treatment in patients who underwent emergency surgery for type a acute aortic dissection. J Cardiothorac Surg. 2020;15:100.

9. Pasparakis M, Vandenabeele P. Necroptosis and its role in inflammation. Nature. 2015;517:311-20.

10. Hou H, Wang Y, Li Q, Li Z, Teng Y, Li J, et al. The role of RIP3 in cardiomyocyte necrosis induced by mitochondrial damage of myocardial ischemia-reperfusion. Acta Biochimica et Biophysica Sinica. 2018;50:1131-40.

11. Linkermann A, Brasen JH, Himmerkus N, Liu S, Huber TB, Kunzendorf U, et al. Rip1 (receptorinteracting protein kinase 1) mediates necroptosis and contributes to renal ischemia/reperfusion 
injury. Kidney Int. 2012;81:751-61.

12. Xu YF, Ma HB, Fang YL, Zhang ZR, Shao J, Hong M, et al. Cisplatin-induced necroptosis in TNFa dependent and independent pathways. Cell Signal. 2017;31:112-3.

13. Luo F, Zhou XL, Li JJ, Hui RT. Inflammatory response is associated with aortic dissection. Ageing Res Rev. 2009;8:31-35.

14. Estrera AL, Miller CC, Goodrick J, Porat EE, Achouh PE, Dhareshwar J, et al. Update on outcomes of acute type B aortic dissection. Ann Thorac Surg. 2007;83:S842-S845, S846-S850.

15. Shashaty MGS, Reilly JP, Sims CA, Holena DN, Qing D, Forker CM, et al. Plasma Levels of Receptor Interacting Protein Kinase-3 (RIP3), an Essential Mediator of Necroptosis, are Associated with Acute Kidney Injury in Critically III Trauma Patients. Shock. 2016;46:139-43.

16. Sureshbabu A, Patino E, Ma KC, Laursen K, Finkelsztein EJ, Akchurin O, et al. RIPK3 promotes sepsisinduced acute kidney injury via mitochondrial dysfunction. JCI insight. 2018;3:e98411.

17. Patino E, Ma KC, Sureshbabu A, Finkelzstein E, Choi AMK, Choi M. Increased Plasma And Urine Ripk3 Levels Correlate With Acute Kidney Injury And Predict Duration Of Kidney Dysfunction During Sepsis. Am J Resp Crit Care. 2017;195:1073-449X.

18. Yoo H, Lee JY, Park J, Yang JH, Suh GY, Jeon K. Association of Plasma Level of TNF-Related Apoptosis-Inducing Ligand with Severity and Outcome of Sepsis. J Clin Med. 2020;9:1661.

19. Wang B, Li J, Gao HM, Xing YH, Lin Z, Li HJ, et al. Necroptosis regulated proteins expression is an early prognostic biomarker in patient with sepsis: a prospective observational study. Oncotarget. 2017;8:84066-73.

20. Hu XM, Li HY, Chen X, Liu HH, Zuo W, Zhang Y, et al. Plasma concentration of receptor-interacting protein kinase-3 as a potential biomarker for diagnosis and prognosis in heart failure. Clinica chimica acta. 2020;509:273-9.

21. Hu XM, Chen X, Pang HY, Liu HH, Chen PP, Shi JL, et al. Plasma levels of receptor interacting protein kinase-3 correlated with coronary artery disease. Chin Med J. 2019;132:1400-5.

22. Chen LW, Dai XF, Lu L, Zhang GC, Cao H. Extensive primary repair of the thoracic aorta in acute type a aortic dissection by means of ascending aorta replacement combined with open placement of triplebranched stent graft: early results. Circulation. 2010;122:1373-8.

23. Kellum JA, Lameire N. Diagnosis, evaluation, and management of acute kidney injury: a KDIGO summary (Part 1). Crit Care 2013;17:204.

24. Kin H, Kawazoe K, Nakajima T, Niinuma H, Kataoka T, Endo S, et al. Perioperative serum procalcitonin concentrations in patients with acute aortic dissection. Eur Surg Res. 2003;35:451-4.

25. Gaudino M, Di Castelnuovo A, Zamparelli R, Andreotti F, Burzotta F, lacoviello L, et al. Genetic control of postoperative systemic inflammatory reaction and pulmonary and renal complications after coronary artery surgery. J Thorac Cardiovasc Surg. 2003;126:1107-12.

26. Vince JE, Wong WW, Gentle I, Lawlor KE, Allam R, O'Reilly L, et al. Inhibitor of apoptosis proteins limit RIP3 kinase-dependent interleukin-1 activation. Immunity. 2012;36:215-27. 
27. Kang TB, Yang SH, Toth B, Kovalenko A, Wallach D. Caspase-8 blocks kinase RIPK3-mediated activation of the NLRP3 inflammasome. Immunity. 2013;38:27-40.

28. Silke J, Rickard JA, Gerlic M. The diverse role of RIP kinases in necroptosis and inflammation. Nat Immunol 2015;16:689-97.

29. Tonnus W, Gembardt F, Latk M, Parmentier S, Hugo C, Bornstein SR, et al. The clinical relevance of necroinflammation-highlighting the importance of acute kidney injury and the adrenal glands. Cell Death Differ. 2019;26:68-82.

30. Gurung P, Anand PK, Malireddi RK, Vande Walle L, Van Opdenbosch N, Dillon CP, et al. FADD and caspase-8 mediate priming and activation of the canonical and noncanonical Nlrp3 inflammasomes. J Immunol. 2014;192:1835-46.

31. Philip NH, Dillon CP, Snyder AG, Fitzgerald P, Wynosky-Dolfı MA, Zwack EE, et al. Caspase-8 mediates caspase-1 processing and innate immune defense in response to bacterial blockade of NF-kappaB and MAPK signaling. Proc Natl Acad Sci USA. 2014;111:7385-90.

32. Zuccari S, Damiani E, Domizi R, Scorcella C, D'Arezzo M, Carsetti A, et al. Changes in Cytokines, Haemodynamics and Microcirculation in Patients with Sepsis/Septic Shock Undergoing Continuous Renal Replacement Therapy and Blood Purification with CytoSorb. Blood Purif. 2020;49:107-13.

\section{Figures}




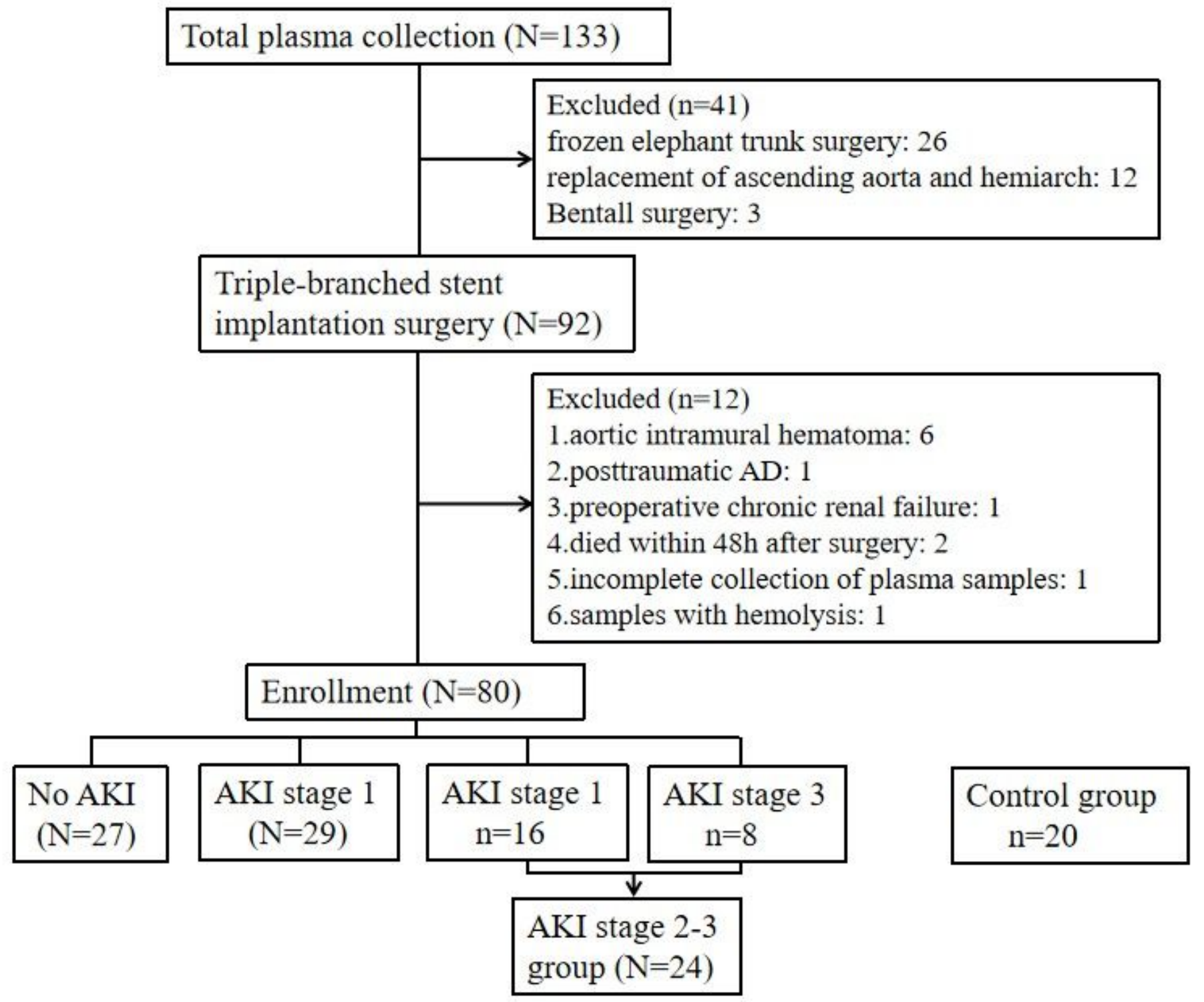

Figure 1

Study flow diagram. 


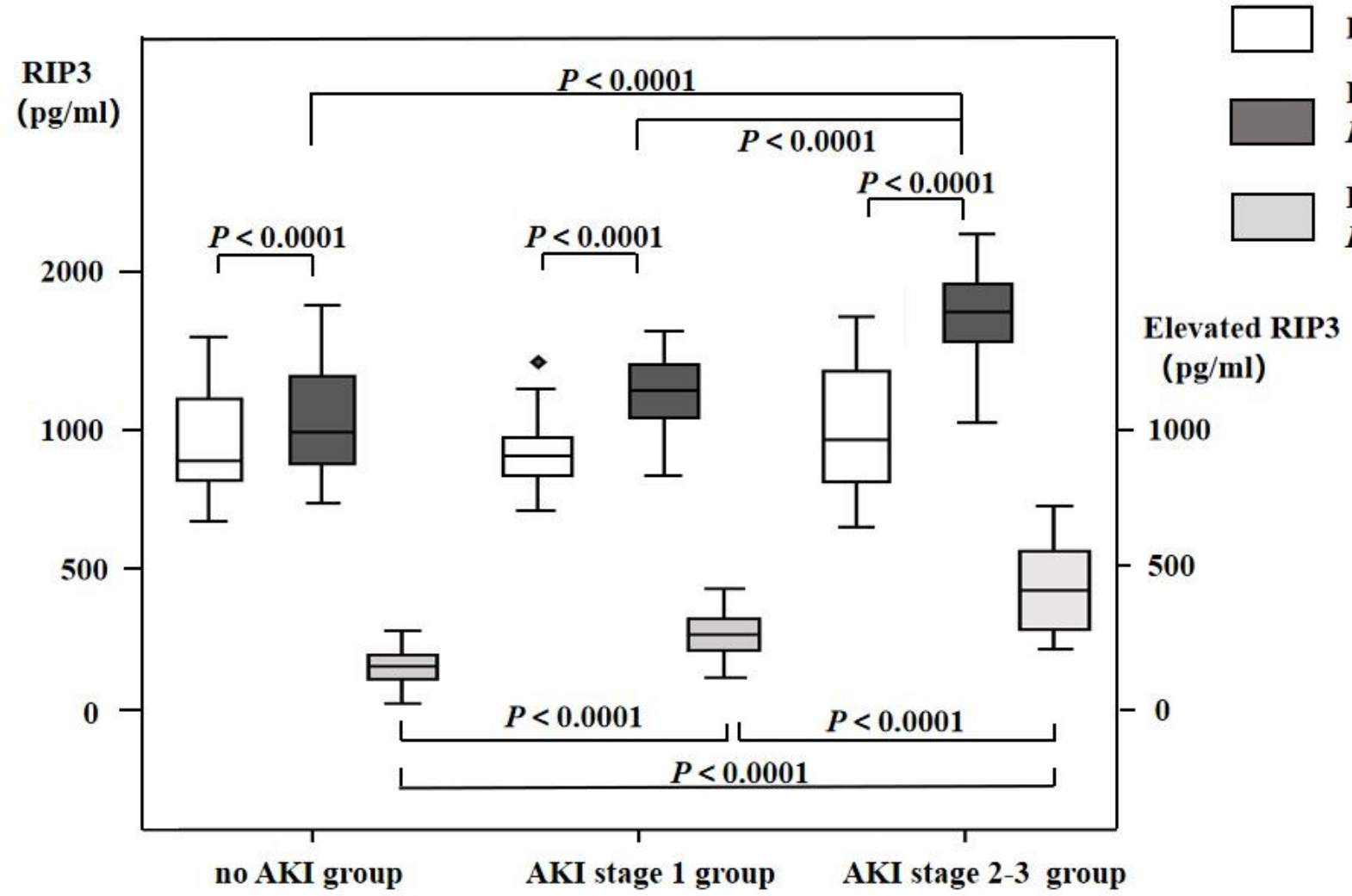

Figure 2

Comparisons of preoperative, postoperative and elevated RIP3 levels among the three groups. This is a double axis chart with boxplot showing preoperative and postoperative RIP3 levels (left vertical axis) and elevated RIP3 levels (right vertical axis). RIP3 levels are presented as median value (black line in the box), interquartile range (box), and maximum and minimum values (upper and lower black line). RIP3= receptor-interacting protein-3. 

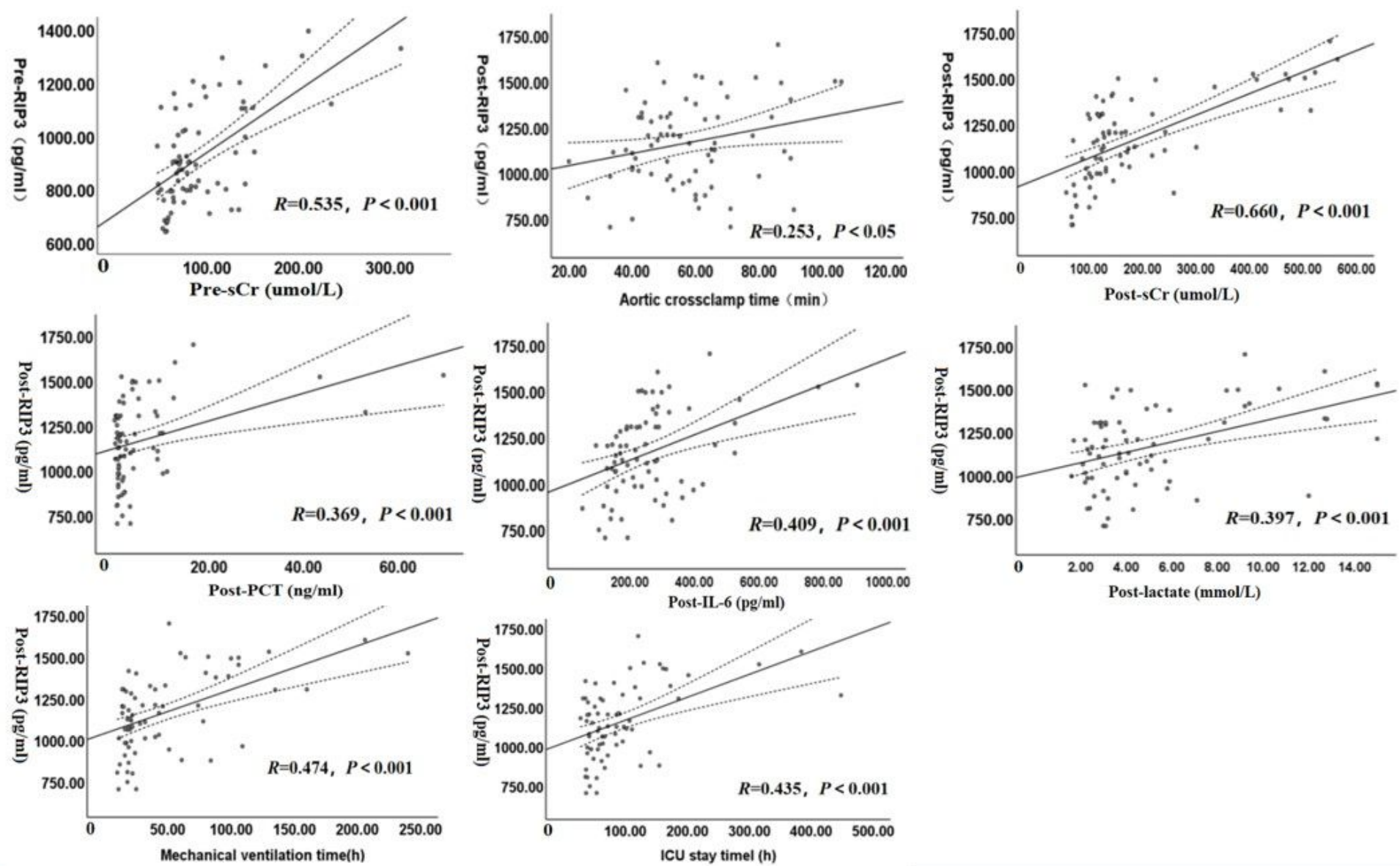

\section{Figure 3}

Correlations between RIP3 levels with sCr, aortic crossclamp time, inflammatory cytokines and clinical outcomes. Linear regression of RIP3 levels association with sCr, aortic crossclamp time, PCT, IL-6, lactate, the mechanical ventilation time and ICU stay time, shown as a black line with dashed line area representing 95\% pointwise $\mathrm{Cl}$. Pre-RIP3=preoperative receptor-interacting protein-3; Pre-sCr=preoperative serum creatinine; Post-RIP3=postoperative receptor-interacting protein-3; Post-s $\mathrm{Cr}=$ postoperative serum creatinine; Post-PCT=postoperative procalcitonin; Post-IL-6=postoperative interleukin-6; Postlactate=postoperative lactate. 


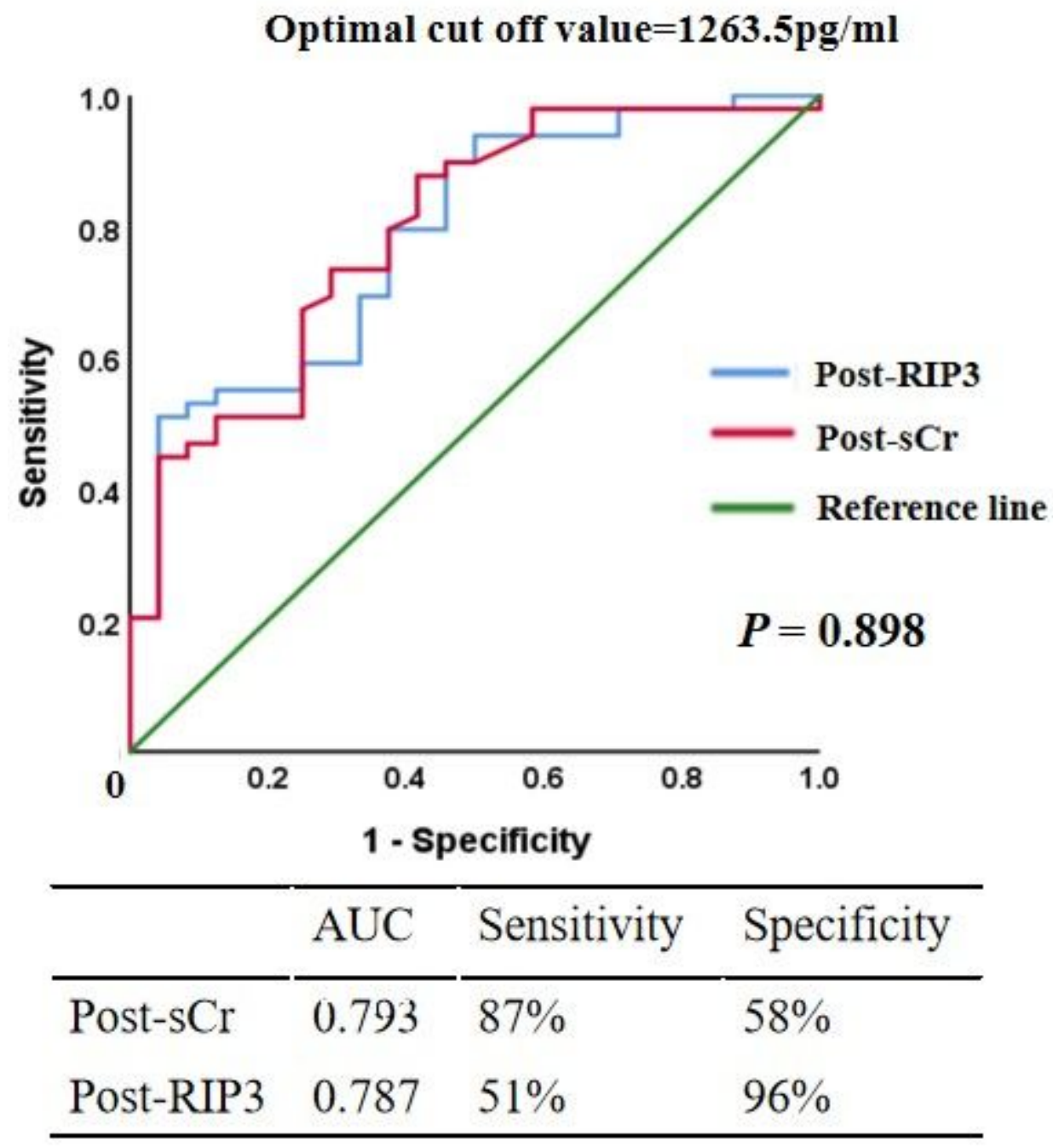

Figure 4

Comparision of the ROC curves. Comparision of the ROC curves between postoperative RIP3 levels and the peak value of postoperative serum creatinine for the diagnosis of postoperative AKI in ADIAD. AUC=The area under the ROC curve, Post-sCr=the peak value of postoperative serum creatinine, PostRIP3=postoperative receptor-interacting protein-3. 


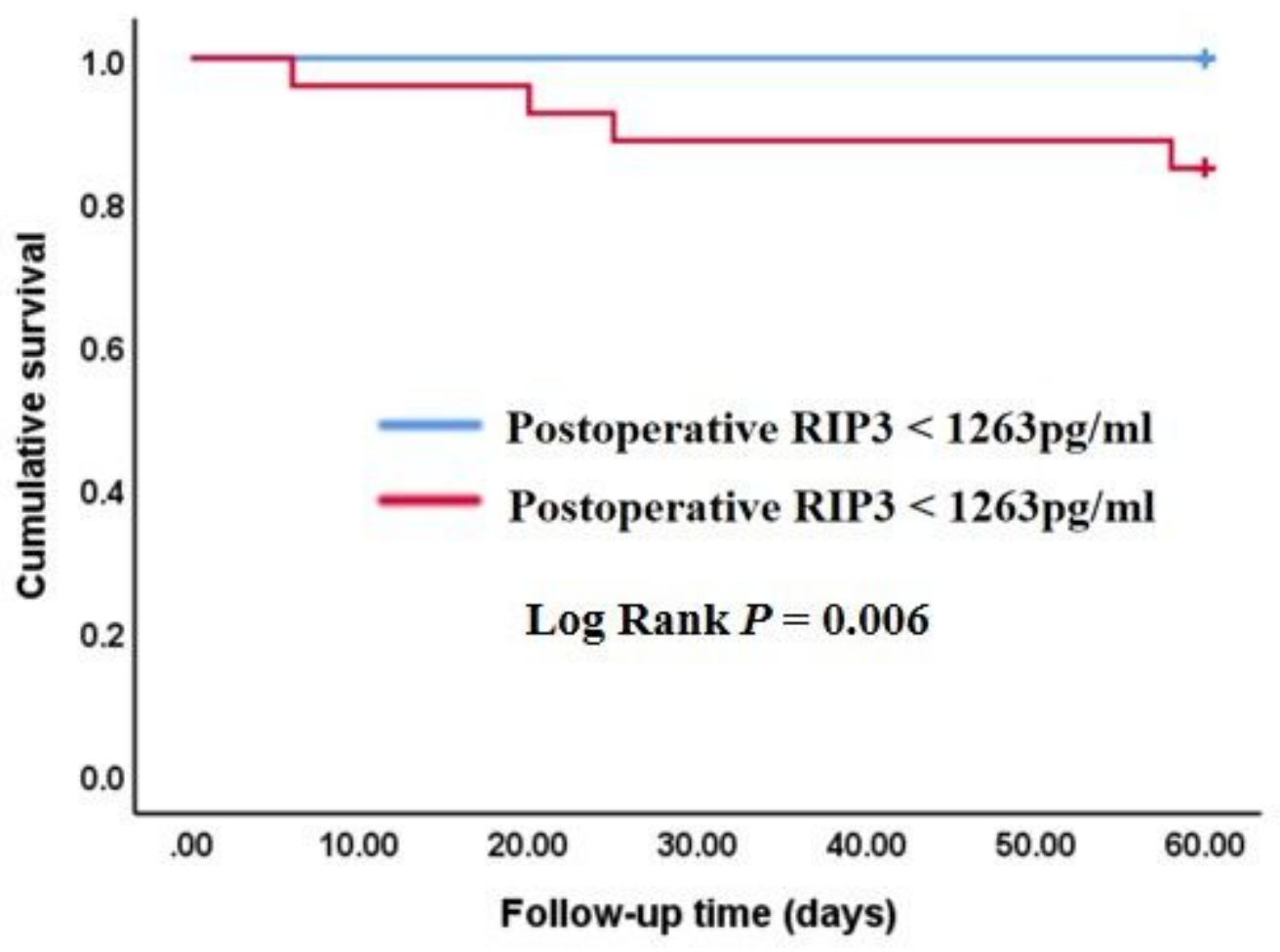

Postoperative RIP3 $<1263 \mathrm{pg} / \mathrm{ml}$
Postoperative RIP3 $>1263 \mathrm{pg} / \mathrm{ml}$ \begin{tabular}{cccc}
52 & 52 & 52 & 52 \\
28 & 26 & 25 & 24 \\
\hline 0 & 20 & 40 & 60 \\
Follow-up time(days)
\end{tabular}

Figure 5

Survival analysis of different postoperative RIP3 levels. In the group of RIP3 levels $>1263 \mathrm{pg} / \mathrm{ml}, 3$ patients died in the hospital, and 1 patient died at 58 days postoperatively.

\section{Supplementary Files}

This is a list of supplementary files associated with this preprint. Click to download.

- Additionalfile1.docx 